\title{
FUSÕES: SEUS IMPACTOS NAS PESSOAS E O PLANEJAMENTO RUMO À SINERGIA
}

Luís Henrique Gianello dos Santos, Willian Pavanelli Ribeiro, Thais Rubia Ferreira Lepre

Universidade do Oeste Paulista - UNOESTE, Curso de Administração, Presidente Prudente, SP. E-mail: luisgianello@gmail.com

\section{RESUMO}

Dentre as estratégias administrativas atuais, uma que ganha destaque por sua ousadia e complexidade é a fusão de empresas que, em síntese, se dá através da união de empresas que passam a responder como uma só. Nota-se então que o sucesso da estratégia depende sinergia do capital humano das fusionadas. Desta forma tal estudo contribui com o planejamento de atividades relacionadas ao processo de fusão no âmbito de gestão de pessoas. Sendo assim, este artigo tem como objetivo identificar o que deve ser analisado, estudado e inserido em uma organização no que se diz respeito ao capital humano, com o intuito de promover melhor sinergia entre equipes integrantes de um processo de fusão organizacional. Para isso fora utilizada a pesquisa qualitativa bem como a metodologia bibliográfica. Com a conclusão foi possível identificar que a resistência à mudanças, choque cultural e o estabelecimento de comunicação adequados são os mais relevantes aspectos.

Palavras-chave: fusão de empresas, sinergia, capital humano, planejamento, mudança.

\section{FUSIONS: THEIR IMPACTS ON THE PEOPLE AND THE PLANNING TOWARDS SYNERGY}

\begin{abstract}
Among the current management strategies, one that stands out for its boldness and complexity is the merger of companies that, in summary, happens through the union of companies that become to respond as one. Note that the success of the strategy depends on synergy of human capital of the fused. In this way, this study contributes to the planning activities related to the fusion process within people management. Thus, this article aims to identify which should be analyzed, studied and inserted in an organization as it relates to human capital, in order to promote better synergy between teams members of a business merger process. For it had been used qualitative research and the literature methodology. With the conclusion was possible to identify that resistance to change, culture shock and the establishment of appropriate communication are the most important aspects.
\end{abstract}

Keywords: business fusion, synergy, human capital, planning, change. 


\section{INTRODUÇÃO}

As fusões sempre estiveram presentes na história, mesmo nos tempos mais remotos, onde ainda não se conceituava esse processo desta maneira. No entanto, apenas nas últimas décadas que essa tendência vem se propagando em virtude da exponencial elevação da competitividade entre organizações no contexto atual, onde um grande número de empresas vem adotando estratégias de fusão organizacional, com o objetivo de se manterem competitivas em um mercado tão dinâmico e mutável.

Tal estratégia está se tornando mais frequente a cada dia em decorrência de suas vantagens relacionadas ao crescimento sinérgico que podem levar a resultados acima da média. No entanto, para que a fusão tenha o retorno esperado, existem muitas variáveis que irão determinar o sucesso ou fracasso da união. Dentre estas, o capital humano destaca-se por ser a força motriz das organizações, dependendo diretamente deste para que a simples união se transforme em resultados.

Sendo os indivíduos peça fundamental para o início de qualquer estratégia, chega-se ao seguinte questionamento: $O$ que deve ser analisado, estudado e inserido em uma organização, no que se diz respeito ao capital humano, com o intuito de promover melhor sinergia entre equipes integrantes de um processo de fusão organizacional?

Tendo esta questão como norte para o desenvolvimento deste artigo, o mesmo tem como objetivo, identificar o que deve ser analisado, estudado e inserido em uma organização, no que se diz respeito ao capital humano, com o intuito de promover melhor sinergia entre equipes integrantes de um processo de fusão organizacional, de modo que este estudo venha a contribuir, direta ou indiretamente, para o planejamento de atividades relacionadas ao processo de fusão no âmbito de gestão de pessoas, trazendo como beneficiários organizações que passam ou pretendem adotar a estratégia de fusão organizacional e preocupam-se com a integração geral das equipes de trabalho, bem como os colaboradores, fornecendo aos mesmos conteúdo para que possam melhor compreender este processo transitório e dar espaço para que estes visualizem oportunidades de crescimento mútuo junto à organização. $O$ estudo tem grande importância pelo fato também de proporcionar o enriquecimento do material relacionado a fusão que, apesar de frequente, pouco se investiga sobre a área.

\section{METODOLOGIA}

Para a desenvolver este artigo utilizou-se o método de pesquisa bibliográfica, visando resgatar a visão de diversos autores a respeito do assunto. Ainda quanto a metodologia, a pesquisa traz uma abordagem qualitativa acerca do tema, de modo a buscar, através destes meios, a melhor resposta à problemática proposta.

\section{RESULTADOS}

Nesta seção serão apresentados todos os resultados encontrados com esta pesquisa, realizada a partir de materiais já publicados.

\section{FUSÕES: SEUS IMPACTOS NAS PESSOAS E SEU PLANEJAMENTO RUMO À SINERGIA}

Quando se trata de estratégias de mercado, um grande leque de possibilidades se abre, entretanto, tais estratégias diferenciam-se principalmente por seu grau de complexidade, por sua amplitude e abrangência de efeito, por seus resultados, velocidade de aplicação, entre muitos outros fatores. A fusão é uma destas estratégias de mercado e para que se possa entender o que vem a ser uma fusão, bem como compreender sua complexidade, abrangência, velocidade e estimar seus resultados, torna-se fundamental compreender como a mesma ocorre. Damasceno (2004, p.68) afirma que "ocorre a fusão de empresas quando, unindo-se, extinguem-se e dão origem a uma nova entidade. Existentes a empresa ' $A$ ' e a empresa ' $B$ ', ambas desaparecem dando 
origem a uma empresa ' $C$ '”. Através disso entende-se que tal estratégia, além de complexa, é arriscada, uma vez que, em sua essência, tem como intuito desfazer as empresas envolvidas para construção de uma nova, implicando assim na necessidade de uma maior cautela por parte do gestor em seus mais diversos aspectos para fazer com que os envolvidos se beneficiem de modo conjunto e sinérgico sem que alguma das partes sejam prejudicadas, e ao mesmo tempo consigam atingir as metas que motivaram a fusão.

Tendo como base esta definição, nota-se que o processo abordado no decorrer desta pesquisa, a fusão tem um grau de complexidade de aplicação elevado, podendo inclusive, segundo Denison (2014), possuir diversos tipos e intensidades em relação a complexidade de implantação, dentre eles: fusões "autônomas", onde poucas mudanças ocorrem para as fusionadas; as fusões de "absorção", onde alguma das partes deve se mudar consideravelmente para assim poder ser incorporada; a fusão "inversa", quando a empresa dominante carece se moldar de acordo com a outra empresa fusionada; as fusões "transformacionais", que exigem mudanças drásticas para todos os integrantes da fusão; e, por fim, a fusão "melhor para ambas", no qual segue comum número moderado de mudanças para que seja encontrado um meio termo entre as empresas.

Nos casos listados por Denison, exceto no das fusões "autônomas", todas exigem mudanças, que vão desde simples adaptações, até as mais complexas reestruturações. Tendo estes aspectos em mente, a pesquisa direciona-se à questão: Como estas mudanças irão afetar o capital humano presente nas organizações? Chiavenato (2010, p.150) traz que: "Quando o administrador decide sobre qualquer mudança a ser feita na organização, ele se defronta naturalmente com a resistência das pessoas." Sendo assim, sabe-se que a resistência é algo natural no processo de mudanças e saber como ela se manifesta e como reduzi-la, torna-se crucial em uma estratégia que envolva uma quantidade de mudanças considerável como o caso da fusão.

\section{FUSÃO E AS PESSOAS}

Em geral, o ato da fusão consiste em "mudanças" e adaptações, seja esta nos processos, na cultura, na estrutura da hierarquia, nos objetivos da empresa, bem como nos objetivos do colaborador, entretanto, com tanta transformação ocorrendo simultaneamente, o administrador encontra a difícil tarefa de fazer com que o plano da fusão dê resultados e, para que isto ocorra, conta com a ação das pessoas, que por sua vez irão colocá-lo em prática, o comportamento dos colaboradores em relação as mudanças, pode ser positivo, não sendo neste caso um problema, ou negativo, e assim ocasionar muitos problemas no decorrer da aplicação do processo de fusão.

Para Oliveira (2010, p.113), a resistência à mudanças refere-se "as atitudes de uma pessoa ou grupo, contrárias a pessoas, ações, situações ou processos". Dito isto, torna-se possível visualizar que as duas variáveis chave para que a fusão culmine em sucesso, possuem uma relação conflituosa, onde, de um lado ocorre a necessidade de mudanças e do outro a reação negativa das pessoas em relação as mesmas.

O surgimento desta resistência decorre de muitos fatores. Chiavenato (2010) classifica-os em três grupos, sendo eles: Aspectos lógicos, que envolvem interesses pessoais, reaprendizagem, tempo de adaptação, entre outros; aspectos psicológicos, que baseiam-se no medo do desconhecido que decorre da dificuldade de compreender o que está acontecendo; e os aspectos sociológicos, que envolvem então valores opostos, desejo de manter colegas que tinha antes da mudança, coalizão política e outros. Vê-se deste modo que todas as causas estão diretamente ligadas aos indivíduos em seus mais variados tipos de interesses, que de modo geral chocam-se com a transformação que a fusão proporciona.

Sendo assim cabe ao gestor estudar previamente o efeito da resistência a mudanças a fim de implantar medidas voltadas a redução de suas causas, visando desta maneira capacitar e orientar os indivíduos para que através disso possa se obter uma melhor integração das equipes envolvidas. 
A partir deste momento, é possível visualizar que as pessoas dentro de uma organização interagem tanto para alcançarem seus objetivos individuais como também os objetivos da organização, ou seja, os coletivos, surgindo então outro fator importantíssimo, presente em todas as organizações, entretanto, que se confronta na aplicação de uma fusão: a cultura organizacional.

\section{FUSÃO E A CULTURA ORGANIZACIONAL}

A cultura organizacional está presente em cada organização, seja esta grande ou pequena, onde cada uma destas possui a sua, ou seja, cada cultura tem sua peculiaridade, sua diferença, de acordo com o ambiente que a circunda ou com as pessoas que nela trabalham.

Segundo a concepção de Dias (2008, p.203), cultura organizacional pode ser conceituada como "um sistema de valores e crenças compartilhados que interage com as pessoas, as estruturas da organização, os processos de tomada de decisões e os sistemas de controle de uma empresa para produzir normas de comportamento [...]"

De tal modo, é possível verificar que a cultura trata-se da identidade de uma empresa e que é uma variável importante no dia-a-dia dessa, que pode influenciar em tomadas de decisão e mudanças que podem ocorrer no ambiente empresarial. Isso se deve ao fato de que as pessoas são diferentes umas das outras e estas compõem, juntas, uma organização.

A situação em questão trata-se, portanto, do quão relevante é a cultura e que esta pode influenciar em um processo de fusão entre empresas.

Tendo em vista que serão "mesclados" os hábitos, valores, crenças e normas de uma Empresa A com uma Empresa B para formar, de duas, uma única e nova, conforme Damasceno (2004), esbarra-se aqui em um outro problema que os gestores devem observar antes de fundir uma corporação, onde o esperado processo sinérgico entre as partes unidas acaba não ocorrendo por conta do fracasso que ocorre no momento da gestão da união das duas culturas.

Complementando tal conceito, Chiavenato (2010, p. 172) faz a seguinte conceituação: “A cultura organizacional ou cultura corporativa é o conjunto de hábitos e crenças, estabelecidos por normas, valores, atitudes e expectativas, compartilhado por todos os membros da organização".

Ao unir duas culturas diferentes, os hábitos, rituais, modo de trabalho e objetivos da empresa e dos colaboradores são alterados para outros distintos daqueles aos quais estavam inseridos. Logo, é necessário que haja um engajamento dos líderes para fazer com que a aproximação das duas partes seja natural e sutil.

Segundo a concepção de Barros (2001, p. 128), a "ausência de consciência clara dos traços da cultura organizacional é uma das razões principais para o choque entre as duas - ou mais culturas das empresas envolvidas nas ações de fusões, aquisições e parcerias". Essa falta de conhecimento por parte dos colaboradores da empresa pode ser minimizada desde que haja um estudo e planejamento prévio por parte dos gestores.

O choque cultural ocorre ao confrontar hábitos e comportamentos de ambientes distintos, onde as pessoas que formam a nova empresa passam a ver e comentar as diferenças da antiga empresa com a qual a sua se fundiu. Isso gera uma segregação cada vez maior de pessoas, em razão da existência de "valores e suposições inconsistentes [...] conhecido como "choque de culturas corporativas"” (DIAS, 2013).

Deve ser dada a atenção necessária nesse ponto pelo fato de que se há um confronto entre as pessoas, não há sinergia, ou seja, "a criação de um todo maior do que a soma de suas partes." (SCHERMERHORN JR., 2007, p. 27). Sem essa união, a nova empresa terá grandes chances de não obter sucesso. Assim, deve haver uma colaboração de todos componentes da empresa, visando atingir o objetivo da fusão organizacional.

Para contornar tal situação e promover a integração cultural, os promotores do processo devem estar atentos à algumas ações que devem ser tomadas com a intenção de minimizar os problemas que podem ocorrer no momento da junção das empresas. 
De acordo com Barros (2001, p. 131) “É preciso unir forças e sensibilizar ambas as partes para obter-se a dinâmica necessária ao processo, incluindo todos seus estágios e desafios naturais." É possível deste modo fazer com que haja uma conscientização e conhecimento das partes de toda a mudança que está prestes a ocorrer, para que possa ser feito um melhor gerenciamento para alcançar um maior engajamento das pessoas envolvidas.

$\mathrm{O}$ apoio pode ser adquirido depois de uma conversa do gestor com seus colaboradores, de modo que, para estes, seja transmitido a ideia de que se pretende atingir com tal operação e a importância da integração entre as equipes. Estratégias e planos também podem ser desenvolvidos com o intuito de diminuir os efeitos negativos que podem surgir no trâmite da operação.

\section{FUSÃO E A COMUNICAÇÃO}

Até este momento, vê-se que tal processo, quando tratado sob a perspectiva da manutenção e desenvolvimento do capital humano, é complexo e exige que se tenha o máximo cautela por parte do gestor, de modo que este possa identificar, prevenir e resolver possíveis problemas. Para tanto torna-se um grande aliado do gestor o fator comunicação, definida por Chinem (2010, p. 01) como o ato de "[...] tornar comum, partilhar, associar, trocar opiniões, conferenciar"; sendo assim, implantar um sistema de comunicação adequado garante que as informações propagadas gerem uma melhor tomada de decisão.

Ainda em Chiavenato (2011), o autor define que a comunicação possui dois propósitos principais: o primeiro deles é proporcionar informações e compreensão para que se possa desenvolver as tarefas; o segundo propósito está em proporcionar atitudes necessárias que promovam a motivação, a cooperação e também a satisfação nos cargos.

Tendo este propósito em mente, é possível notar que a comunicação pode ser usada com o intuito de aperfeiçoar o ambiente a fim de conduzir os indivíduos a um melhor espírito de equipe e isso, consequentemente, pode culminar em resultados acima da média.

\section{CONSIDERAÇÕES FINAIS}

Trazendo como problemática a questão "O que deve ser analisado estudado e implementado em uma organização, no que se diz respeito ao capital humano, com o intuito de promover melhor sinergia entre equipes integrantes de um processo de fusão organizacional?", foi possível concluir que o processo de fusão traz à empresa e a seus colaboradores uma quantidade relevante de mudanças, sendo, deste modo, um dos maiores problemas quando se adota tal estratégia, principalmente entre os indivíduos envolvidos neste processo, cabendo ao gestor justamente analisar previamente os aspectos que afetam diretamente o estabelecimento da sinergia. $\mathrm{O}$ mais notável destes fatores está relacionado à resistência à mudanças, que é algo que surgirá naturalmente no decorrer do processo, sendo então o fator que deve ser mais bem estudado e analisado pelo gestor, com o objetivo de reduzi-lo, uma vez que este contribui com o agravamento de outros fatores negativos que afetam o resultado positivo de um processo de fusão.

Cabe ressaltar que outro ponto fundamental está relacionado ao choque de culturas ocasionado durante o processo, uma vez que as fusões se dão por meio da somatória de empresas portadoras de culturas próprias, sendo comum a ocorrência conflitos de interesses tanto pessoais como profissionais, podendo trazer o distanciamento das equipes, e o que era para ser sinérgico torna-se algo conflituoso, competitivo ou até mesmo impositivo por alguma das partes que poderá impor a cultura do seu modo, desconsiderando assim pontos fortes advindos das outras culturas, não ocasionando também, neste caso, a sinergia, ficando por conta do gestor a intermediação cultural, bem como a inserção de uma cultura que consiga assimilar os pontos 
fortes de cada uma, criando assim um conjunto cultural dinâmico e integrado, evitando desta maneira o choque cultural.

A comunicação é outro ponto que merece destaque, pois é através da aplicação adequada da mesma que muitos dos problemas listados anteriormente podem ser evitados, podendo ainda contribuir com o nascimento do espírito de equipe entre os envolvidos.

Sendo assim o artigo consegue identificar que a maior parte das ações que devem ser estudadas e analisadas e/ou inseridas nas organizações em relação ao capital humano que deverão estar voltadas a resistência a mudança ao choque de culturas e também aos sistemas de comunicação, onde cada um desses contribuem ou prejudicam o estabelecimento da sinergia entre as equipes de trabalho envolvidas no processo. Certamente existem outros fatores que afetam o estabelecimento da sinergia, entretanto todos estão ligados, de forma direta ou indireta, com alguma destas três vertentes.

\section{REFERÊNCIAS}

BARROS, B. (Coord.). Fusões, aquisições \& parcerias. São Paulo: Atlas, 2001.

CHIANEVATO, I. Administração nos novos tempos. 2. ed. Rio de Janeiro: Elsevier, 2004.

CHIAVENATO, I. Gestão de pessoas: o novo papel dos recursos humanos nas organizações. 3.ed. Rio de Janeiro: Elsevier, 2010.

CHIAVENATO, I. Introdução a teoria geral da administração. 8. ed. Rio de Janeiro: Elsevier, 2011.

CHINEM, R. Introdução à comunicação empresarial. Saraiva, 2010.

DAMASCENO F. A.V. Igualdade de tratamento no trabalho - isonomia salarial. Barueri: Manole, 2004.

DENISON, D. et al. A força da cultura organizacional nas empresas globais: como conduzir mudanças de impacto e alinhar estratégia e cultura. Rio de Janeiro: Elsevier, 2012.

DIAS, R. Sociologia das organizações. São Paulo: Atlas, 2008.

OLIVEIRA., M. A. Comportamento Organizacional para Gestão de Pessoas: como agem as empresas e seus gestores. São Paulo: Saraiva, 2010.

SCHERMERHORN JR., J. Fundamentos de comportamento organizacional [recurso eletrônico]. 2. ed. Porto Alegre: Bookman, 2007. 